\title{
Escritores intelectuales y la política cultural en el gobierno de Salvador Allende. Los aportes del Taller de escritores de la Unidad Popular (1970-1973)
}

\author{
Intellectual writers and cultural policy in Salvador Allende's government \\ The contributions of the Writers Workshop of the Popular Unity (1970-1973)
}

\author{
Laura Briceño Ramírez*
}

\begin{abstract}
Resumen: Este artículo, tiene como objetivo analizar la propuesta cultural de un grupo de escritores que, bajo el autodenominado Taller de escritores de la Unidad Popular firmaron y publicaron en la revista Cormorán, en diciembre de 1970, el documento Politica Cultural: por la creación de una cultura nacional y popular. Se analizan los diagnósticos realizados por los escritores, las premisas fundantes de lo que sería la «nueva cultura» y el papel que les correspondía a los intelectuales en este proceso. Se trata de un ejercicio analítico que se adentra en el proceso de recepción, producción y circulación de las ideas sobre política cultural de este grupo, con el fin de poner en evidencia el desarrollo de otros proyectos que, aunque no fueron considerados por el gobierno de Salvador Allende, son factibles de historizar, ya que expresan representaciones, imaginarios y proyecciones culturales de intelectuales que decidieron, desde su adhesión y compromiso con la Unidad Popular, contribuir a la construcción de lo que sería la «nueva cultura socialista».
\end{abstract}

Palabras clave: escritores-intelectuales, política cultural, Taller de escritores de la Universidad Católica, Unidad Popular.

\begin{abstract}
The objective of this article, is to analyze the cultural proposal of a group of writers who signed and published in the magazine Cormorán, in December 1970, the document, Politica Cultural: por la creación de una cultura nacional y popular, under the self-styled Taller de escritores de la Unidad Popular. We analyze the diagnoses made by the writers, the foundational premises of what the "new culture" would be, the role that corresponded to the intellectuals in this process. It is an analytical exercise that delves into the process of reception, production and circulation of ideas on cultural policy of this group, in order to highlight the development of other projects that, although they were not considered by the government of Salvador Allende, are feasible to historicize, since they express representations, imaginaries and cultural projections of intellectuals who decided, from their adhesion and commitment to Unidad Popular, to contribute to the construction of what would be the "new socialist culture".
\end{abstract}

Key words: writers-intellectuals, cultural policy, Writers Workshop of the Catholic University, Popular Unity.

Recibido: 5 septiembre 2018 Aceptado: 23 noviembre 2018

\footnotetext{
* Chilena. Magíster en Historia de la Universidad de Santiago de Chile. Este artículo se desprende de mi tesis Magíster titulada: Escritores intelectuales y los debates sobre el proyecto cultural de la Unidad Popular. Prácticas de sociabilidad y campo intelectual: una mirada desde el Taller de escritores de la Universidad Católica de Chile (1959-1973). Correo electrónico: lbricenoramirez@gmail.com.
} 


\section{Introducción}

Durante la década de los sesenta y, especialmente en los años de la Unidad Popular (1970-1973), hubo una inusitada reflexión en la izquierda chilena ${ }^{1}$ sobre la necesidad de una profunda transformación cultural. Artistas e intelectuales buscaron establecer parámetros para refundar un nuevo sistema, en sintonía con la movilización y politización de vastos sectores de la sociedad chilena. Como señala Rolando Álvarez, "el país experimentaba el desarrollo de una subjetividad cotidiana que cuestionaba las prácticas culturales dominantes"2, estableciendo nuevos significados de lo político, social y cultural.

Los planteamientos de intelectuales y artistas partían del diagnóstico de una cultura dependiente, subdesarrollada y carente de una identidad propia, consecuencia del desarrollo de una cultura de masas, impulsada por la burguesía nacional aliada al capital extranjero. De este diagnóstico, derivaron una serie de conceptualizaciones, premisas y proyecciones cuyo objetivo era orientar los caminos hacia construcción de una «nueva cultura». Nadine Canto, señala que hubo una articulación entre cultura y política bajo el paradigma epistémico del marxismo que intentaba materializar esa reflexión, exigiendo que la teoría sirviera como dispositivo para la modificación del orden social 3 .

Desde otro punto de vista, Martín Bowen sostiene que la izquierda intelectual sobredimensionó su propia lectura ideológica de los discursos y prácticas sociales, olvidando por completo, la posibilidad de que el público, receptor de esos contenidos, pudiese jugar un papel más activo, en vez de ser un mero recipiente de la «nueva cultura» ${ }^{4}$.

El autor sostiene, que las propuestas culturales se centraron en la construcción de una cultura que reeducaría a los sectores populares, estableciendo nuevos imaginarios sociales en línea con el socialismo. Sin embargo, la izquierda no se habría enfocado en los verdaderos intereses del pueblo, pues su propuesta, al ser un proyecto "inmunológico", buscaba reemplazar la cultura burguesa, sin considerar lo que hasta la fecha existía en materia cultural. Bowen manifiesta que los intelectuales fueron incapaces de comprender las estructuras simbólicas y culturales con las que el pueblo se expresaba" 5 , habiendo una distancia entre la propuesta cultural y el mundo popular.

Lo anterior se habría producido, porque "en cierta medida, esta izquierda no comprendió al sujeto popular al que se dirigía, a excepción de contados casos. Este desencuentro provenía, en gran parte, de la escisión producida entre las Ciencias Sociales y el resto de las manifestaciones culturales de su presente, en tanto las desestimaba como productos de una superestructura podrida por el capitalismo"6.

Si bien era necesario transformar la cultura, la crítica de Bowen obedece a que los intelectuales comprometidos con el cambio social, no establecieron puentes que comunicaran los intereses del pueblo con el proyecto cultural de la Unidad Popular, presentándose la idea de hacer un cambio radical, desde el punto de vista ideológico, pero sin un plan de trabajo que considerara las características de la cultura popular. Es decir, la discusión se desarrollaba en un plano teórico, que no supo encausarse hacia la práctica.

En otra posición, Rolando Álvarez sostiene que la izquierda chilena carecía de una teorización que complejizara la creación de una «nueva cultura», ya que la transformación cultural se planteaba desde el determinismo económico, entendiendo que la superestructura era reflejo de lo económico, "lo que le

\footnotetext{
1 Martín Bowen, "El proyecto sociocultural de la izquierda chilena durante la Unidad Popular. Crítica, verdad e inmunología política", Nuevo Mundo Mundos Nuevos, 21 de enero 2008, https://nuevomundo.revues.org/13732

2 Rolando Álvarez, "Trabajos voluntarios: el «hombre nuevo» y la creación de una nueva cultura en el Chile de la Unidad Popular", Julio Pinto (Ed.) Fiesta y drama. Nuevas historias de la Unidad Popular. Santiago, LOM, 2014, 174.

${ }^{3}$ Nadine Canto, "El lugar de la cultura en la vía chilena al socialismo. Notas sobre el proyecto estético de la Unidad Popular". Pléyade, 9, Enero-Junio 2012, 155.

${ }^{4}$ Bowen, op, cit.

5 Ibíd.

${ }^{6}$ Ibíd.
} 
impedía una mirada más compleja sobre el toma de conciencia de la población"7. De acuerdo con el autor, principalmente el Partido Comunista (PC), proponía reproducir en el ámbito cultural la "batalla de la producción", planteando que el trabajo forjaría una nueva conciencia y, por lo tanto, una «nueva cultura».

Para el PC, la transformación cultural debía estar en línea con la política económica del gobierno de la Unidad Popular y debía, contribuir a la transformación estructural del país. Sin embargo, como señala Rolando Álvarez, el problema estaba en la lectura y procedimiento que hacían los partidos políticos y el gobierno respecto a cómo el pueblo se desarrollaba en términos culturales y cuáles debían ser los caminos hacia la transformación cultural.

En ese sentido, César Albornoz realiza una revisión a las iniciativas y actividades culturales de la Unidad Popular, estableciendo que existían posturas divergentes entre los intelectuales y el gobierno. Por un lado, el gobierno estimulaba la creación y las actividades culturales a través del Departamento de Cultura de la Presidencia, que era dirigido por Waldo Atías, sumándose a éste, entre otros, el movimiento de la Nueva canción cbilena. Y, por otro lado, había múltiples manifestaciones que no necesariamente respondían a la propuesta del gobierno, como fue el caso de la agrupación Los Jaivas o los artistas que participaron en el Festival de Piedra Roja, que emulaban el festival estadounidense Woodstock.

Ante esta diversidad de expresiones, César Albornoz plantea que el gobierno de la Unidad Popular, en el ámbito cultural tenía una tarea compleja, "si bien el objetivo era construir una cultura donde el protagonista fuera el pueblo y los trabajadores, debía ser cuidadosa con la libertad creativa esencial para toda la producción cultural. Y tempranamente hubo voces de alerta sobre estas posibles dificultades"8.

Una de esas voces fue la de un grupo de escritores que, bajo el rótulo del Taller de escritores de la Unidad Popular, firmaron y publicaron en la revista Cormorán, en diciembre de 1970, una propuesta que pretendía aportar al debate sobre cómo debía ser la «nueva cultura» en la vía chilena al socialismo y definir el papel de los artistas e intelectuales en el proyecto cultural de la Unidad Popular. Esto generó una discusión sobre cómo debía ser la política cultural del gobierno, principalmente con el PC, que por medio de su encargado cultural Carlos Maldonado y el escritor Volodia Teitelboim, en la Asamblea de trabajadores de la Cultura, desarrollada por el partido en septiembre de 1971, expresaron sus reparos a la propuesta de los escritores, planteado que la «nueva cultura» debía tener un carácter proletario.

Frente a este escenario, César Albornoz sostiene que "la política gubernamental parecía no responder a las expectativas cifradas, pero objetivamente la actividad cultural se plasmaba en el ambiente" . Ello, explica la aparición de la propuesta de los escritores, al mismo tiempo que otros intelectuales discutían sobre la política cultural, ejemplo de ello son los trabajos del grupo que estudiaba las comunicaciones e ideología en el Centro de Estudios de la Realidad Nacional (CEREN) ${ }^{10}$, dirigidos por Armando Mattelart, mientras proliferaban acciones culturales de toda índole, como los Centros de Cultura Popular (CCP), que con patrocinio del gobierno se instalaron en barrios, sindicatos y escuelas.

Frente a ello, en esta investigación, nos proponemos examinar la propuesta cultural de los escritores asociados al Taller antes mencionado y los debates que derivaron de ésta, observando las ideas circulantes sobre cultura, los mecanismos que se creían necesarios para llevar a cabo los cambios y los actores que participaron en la discusión.

Como premisa, sostenemos que estos escritores, desde una posición intelectual y un marxismo heterodoxo, hicieron un diagnóstico de la realidad cultural, proponiendo vías para su transformación y definiendo a los intelectuales y artistas como una vanguardia dentro del proyecto cultural de la Unidad

\footnotetext{
7 Álvarez, op, cit., 174.

8 César Albornoz, "La cultura en la Unidad Popular: Porque esta vez no se trata de cambiar un presidente". En: Julio Pinto, (Coordinador-editor), Cuando bicimos historia. La experiencia de la Unidad Popular. Santiago, LOM, 2006, 151.

9 Albornoz, op, cit., 165.

10 Carla Rivera, "Diálogos y reflexiones sobre las comunicaciones en la Unidad Popular. Chile, 1970-1973", Historia y comunicación social, vol. 20, $\mathrm{N}^{\circ} 2,2015,350$. http://revistas.ucm.es/index.php/HICS/article/view/51388/47668
} 
Popular. Este posicionamiento, debió enfrentar una serie de críticas provenientes, entre otras, del PC, partido que defendía el desarrollo de una «cultura de masas» proletaria, definida por el aparato burocrático, mientras que el grupo de literatos planteaba la necesidad de flexibilizar esa postura, asumiendo al gobierno de Salvador Allende como una transición al socialismo, por lo que en primera instancia era necesario construir un «Frente Único» que preparara las condiciones objetivas y subjetivas para que el pueblo se incorporara al socialismo y luego construir la «nueva cultura». Estas diferencias, generaron discusiones en torno al papel de los intelectuales en este proceso, cómo vincular al pueblo y el carácter que debía tener la cultura socialista.

La participación de este grupo de escritores en la discusión sobre la política cultural durante la Unidad Popular, supuso un ejercicio intelectual en el que dieron cuenta, en primera instancia, de su adhesión al proyecto que encabezaba Salvador Allende y en segundo lugar, expresaron sus ideas sobre cómo debía ser la cultura en la transición al socialismo. Esta acción, expresa que estos escritores estaban dispuestos a traspasar las fronteras de su disciplina y opinar críticamente sobre los proyectos de transformación de la realidad, asumiendo con ello una función social crítica.

Claudia Gilman sostiene que durante los años sesenta hubo una vinculación entre la literatura y el campo político en diversos países del continente, señalando que este período "constituyó el parámetro de la legitimidad de la producción textual y el espacio público fue el escenario privilegiado donde se autorizó la voz del escritor, convertido así en intelectual"11. Esta autorización, para François Dosse, se manifestó a través del compromiso de los intelectuales con la lucha política e ideológica de la época, lo cual los constituyó en una elite creativa al interior de la sociedad ${ }^{12}$.

La figura del escritor, que adhería a los proyectos revolucionarios de los años sesenta y setenta, se caracterizó por su vinculación con la esfera pública a través de la publicación de su opinión, expresando su compromiso con la transformación de la realidad social. Este compromiso, no necesariamente iba en línea con lo expresado por los partidos políticos en los que militaban, en algunos casos se ubicó al margen de éstos. Claudia Gilman sostiene, que "la doctrina del compromiso aseguraba a los intelectuales una participación en la política sin abandonar el propio campo, al definir la tarea intelectual como un trabajo siempre, y de suyo, político"13. Aquello, supone que el intelectual tiene cierto poder para opinar respecto de la realidad, entendiendo que su legitimidad no estaría dada sólo por pronunciar su opinión en el ámbito público, sino también porque es reconocido por el sistema político. En ese sentido, Germán Alburquerque sostiene que el intelectual es un "sujeto portador de un poder específico, que lo dota de un estatus que lo habilita para dialogar con otros entes, también en posesión de poderes determinados" 14.

Se puede sostener, que el escritor intelectual en este periodo, intervino en el campo político por su adhesión y compromiso con el proyecto revolucionario socialista. Ello implicó, un posicionamiento entre el campo cultural y político desde donde produjeron una serie de ideas que circularon a través de medios de comunicación, con la clara intención de aportar al debate crítico sobre las transformaciones estructurales que se creían necesarias, evidenciando el poder de sus opiniones, al ser leídas y pelemizadas por otros intelectuales y el campo político.

Inscribiendo esta investigación en la Historia Intelectual, François Dosse señala, que "el estudios de los modos de compromiso y de los discursos sostenidos por los intelectuales necesita, por parte del historiador, una acción vigilante del contexto, a las posiciones discursivas y a las fluctuaciones semánticas"15. Es decir, tener en cuenta cuándo, cómo y para qué los intelectuales producen las ideas, considerando conceptos utilizados y sus significados, de acuerdo al periodo en el que fueron definidos. A ello, agregamos, que debemos tener en cuenta las prácticas de sociabilidad que posibilitaron su creación

\footnotetext{
11 Claudia. Gilman, Entre la pluma y el fusil. . Debates y dilemas del escritor revolucionario en América Latina, Buenos Aires, Siglo XXI editores Argentina, 2003, 29.

12 Dosse, François. La marcha de las ideas. Historia de los intelectuales, historia intelectual. PUV. Valencia, 2006, 19.

13 Gilman, op, cit., 72.

14 Germán Alburquerque, La trinchera letrada. Intelectuales latinoamericanos y la Guerra Fría, Ariadna, Santiago, $2011,9$.

${ }^{15}$ Dosse, op, cit., 77.
} 
y circulación, sin olvidar que la producción ideática está envuelta en un sistema de relaciones e intereses que influye en su existencia ${ }^{16}$. Esto quiere decir, que nos interesa analizar el contenido del documento del Taller de escritores de la Unidad Popular, sus proyecciones y extensiones, indagando en los diálogos que se entablaron a partir de su publicación, considerando a actores y sectores políticos.

Por lo tanto, la operación metodológica de esta investigación, se centrará en las condiciones de producción, apropiación y circulación de las ideas del grupo de escritores, teniendo en cuenta que éstas contienen representaciones e imaginarios que se proyectaron hacia el futuro y por lo tanto son posibles de historizar. Para ello, revisaremos en primer lugar el Taller de escritores de la Universidad Católica, donde se reunía el grupo que publicó la propuesta cultural; en segundo lugar, analizaremos las ideas que contenía el documento Política Cultural, para comprender cuál era su diagnóstico, qué debía hacerse en esta materia para contribuir a la vía chilena al socialismo y el papel que le correspondían a los intelectuales en el proyecto cultural del gobierno de Salvador Allende; en tercer lugar, examinaremos algunas profundizaciones de las ideas de la propuesta en el libro La cultura en la vía chilena al socialismo (1971), publicado por algunos de los firmantes del documento; y en cuarto lugar, examinaremos la discusión que tuvieron estos escritores con el PC respecto de los intelectuales, la creación del «Frente Único» y la revolución cultural.

\section{Una propuesta cultural en el Taller de Escritores de la Universidad Católica.}

El Taller de escritores de la Universidad Católica (UC), fue una experiencia literaria que surgió dentro de los cambios que experimentó esta universidad en el proceso de reforma iniciado en 1967. Este proceso, gatillado por el descontento y movilización de un grupo de estudiantes conducidos por la Federación de Estudiantes de la Universidad Católica, tenía como objetivo promover cambios en el vínculo de la universidad con la sociedad y la elección del gobierno universitario, solicitando la participación de todos los estamentos.

Luego de meses de discusión y tensión entre las autoridades y los estudiantes, el 11 de agosto de 1967, la Federación de Estudiantes llevó a cabo la toma de la casa central, desplegando el famoso cartel, Chileno: El Mercurio miente, como una forma de responder a las editoriales que Agustín Edwards, dueño del diario, publicaba en contra del movimiento estudiantil. Al tratarse de una universidad perteneciente a la Iglesia Católica, el Vaticano nombró como mediador del conflicto al Cardenal Raúl Silva Henríquez, quien luego de una serie de negociaciones logró, el 21 de agosto del mismo año, que los estudiantes bajaran la toma, aceptando el petitorio de reforma y nombrando como Prorrector al académico Fernando Castillo Velasco, quien posteriormente en un claustro conformado por el 25\% de estudiantes fue elegido Rector, siendo el primer laico en ocupar ese cargo.

Fernando Castillo Velasco, arquitecto y militante de la Democracia Cristiana, asumió la tarea de reformar la Universidad, cuestión que quedó plasmada en el Plan de Desarrollo (1968-1970). En este documento se indican como objetivos, que "se acentuará la importancia de la ciencia, la democratización en el mando y el acceso a las aulas; especial realce se concede a la función crítica frente a las alienaciones que asaltan al hombre y a los grupos sociales, y mayor acento se dispensa al papel de inserción de la Universidad en los procesos que suceden en su exterior" 17.

A partir de dicho plan y con la finalidad de conectar a la Universidad con la sociedad, se creó la Vicerrectoría de Comunicaciones, la que fue dirigida por el sociólogo David Benavente. Esta Vicerrectoría albergó una serie de iniciativas que buscaban cumplir con aquel mandato, siendo una de ellas el Taller de escritores propuesto por Luis Domínguez, director de la Escuela de Periodismo de la

\footnotetext{
16 Pilar González, "La «sociabilidad» y la historia política". Nuevo Mundo. Mundos Nuevos. BAC - Biblioteca de Autores del Centro. 17 febrero 2008. https://nuevomundo.revues.org/24082

17 Jaime Rosenblitt, "La reforma universitaria, 1967-1973”, Cátedra Liderazgo Social (14 October-18 November 2010), Memoria Chilena. http://www.memoriachilena.cl/archivos2/pdfs/MC0014015.pdf.
} 
UC. Además del Taller, la Vicerrectoría creó Ediciones Nueva Universidad dirigida por Cristián Santa María Santa Cruz, la que en 1969 editó El cuento cbileno actual de Alfonso Calderón, Las décimas de Violeta Parra, con la Editorial Pomaire S.A., en septiembre de 1970, Los Artefactos y Poesía rusa contemporánea, una antología bilingüe de Nicanor Parra, en 1972, entre otras obras.

El director de la Ediciones Nueva Universidad en la presentación de Las Décimas de Violeta Parra planteó que

La Universidad Católica de Chile sabe su misión; conciencia crítica de una nación y de un continente herido. Siente y toma la mano de un pueblo acreedor de los valores mudos o amordazados de su propia cultura. Hacer universidad es, hoy y aquí, buscar en las corrientes subterráneas, para proclamar, libre y proféticamente nuestro destino en un mundo que se gesta, olvidando con frecuencia la voz latinoamericana ${ }^{18}$.

El espíritu de reforma que inundó a la UC entre 1967 y 1973, permitió que se transformara en un espacio abierto para la creación artística y cultural, de acuerdo a los objetivos fijados en el Plan de Desarrollo. En ese sentido, es posible sostener que el Taller de Escritores de la Universidad Católica fue un producto de la reforma, en donde los escritores convivieron con las distintas iniciativas de la Vicerrectoría de Comunicaciones y de la universidad.

Un ejemplo de ese vínculo, fue la relación que existió entre algunos escritores del Taller y el Centro de Estudios de la Realidad Nacional (CEREN), que se puso en funcionamiento el 4 de septiembre de 1968 y que a poco andar se transformó en "un centro académico estandarte de la reforma, encargado de diseñar programas educativos interdisciplinarios, acorde a los desafíos y necesidades nacionales" ${ }^{19}$. El centro se planteó dos líneas de acción: la académica, abocada a la investigación y docencia, y la difusión de conocimientos a través de publicaciones y seminarios ${ }^{20}$. Luis Domínguez, director y organizador del Taller, hizo clases en el centro y el escritor Hernán Valdés, que era parte de ese Taller, fue miembro del comité de redacción de los Cuadernos de la Realidad Nacional de CEREN, mientras que José Joaquín Brunner, quien trabajaba en el centro de estudios participó en el Taller de escritores ${ }^{21}$.

$\mathrm{Al}$ respecto, Enrique Lihn sostenía en el libro de Soledad Bianchi La memoria: modelo para armar, que él hacía clases en el centro y que el Taller tenía "muchas relaciones con el CEREN que era muy vivo, dedicado a la investigación sobre Chile, y que tenía, asimismo, mucha flexibilidad (...) había otros escritores: Antonio Avaria, Hernán Valdés, ellos trabajaron en el CEREN que también significaba una apertura de la universidad a la sociedad al hacer investigaciones pertinentes con lo que ésta era" 22.

El Taller comenzó sus actividades en la Casa Central de la UC a fines de 1969, con Enrique Lihn y Jorge Edwards asesorando las áreas de poesía y prosa respectivamente. Luis Domínguez sostuvo, que "el Taller fue una gran realización de la Católica, y creo que tenía mucho que ver con el Rector, con Castillo, con su mentalidad que era muy de ver a la Universidad volcada en la sociedad; a él siempre le importaba eso. Y como esta Vicerrectoría era algo nuevo, podía tener cualquier cosa en materia de comunicaciones" 23 .

Si bien el Taller se concibió en la Vicerrectoría de Comunicaciones, Domínguez enfatizó que éste "no miraba hacia dentro de la universidad, nosotros no tuvimos muchas relaciones con el Departamento de Letras (...) la idea del taller original era ir hacia afuera, hacia la sociedad"24. El Taller, era una invitación para que los escritores conformaran una comunidad en torno de la Universidad, sin necesariamente responder a los lineamientos de la casa de estudios, salvaguardando su independencia creativa y

\footnotetext{
18 Soledad Bianchi, La memoria: modelo para armar, Santiago, Centro de investigaciones Diego Barros Arana, $1995,220$.

${ }^{19}$ Rivera, op, cit. 350.

20Ibid.

21 Bianchi, op. cit., 205.

22 Ibid.

23 Ibíd.

${ }^{24}$ Bianchi, op, cit., 207.
} 
constituyéndose en un espacio de socialización entre escritores consagrados y los que se aventuraban en las letras.

Participaron diversos escritores de la llamada generación del 60, destacando Antonio Skarmeta, Poli Délano, Ariel Dorfman, Hernán Valdés, Federico Schopf, Martín Cerda, Waldo Rojas, Germán Marín, entre otros; mientras que Enrique Lihn, Cristián Huneeus y Jorge Edwards pertenecían a la llamada generación del 50.

Junto con integrar el Taller, los escritores antes mencionados, habitaron otros espacios políticoculturales durante los años de la Unidad Popular. Germán Marín, colaboró como crítico literario en la revista Punto Final; Ariel Dorfman, participó en CEREN, coautor con Armand Mattelart del libro Para leer al Pato Donald. Comunicación de masas y colonialismo, animador en el canal de televisión de la Universidad de Chile; Hernán Valdés, redactor de los Cuadernos de CEREN; Antonio Skarmeta, ganador del premio Casa de las Américas en 1969, por Desnudo en el tejado, fue parte del programa Libro Abierto del canal de televisión de la Universidad de Chile e integrante del comité editorial de la revista Quinta Rueda de Quimantú; Hernán Loyola, crítico literario en el periódico del comité central del Partido Comunista El Siglo; Alfonso Calderón, asesor literario de Editorial Quimantú; Waldo Rojas, crítico literario del Boletín de la Universidad de Chile y colaborador de la revista Cormorán; Federico Schopf, académico del Instituto Pedagógico de la Universidad de Chile y crítico literario en la revista Abora.

En términos de militancia política, Ariel Dorfman y Antonio Skarmeta eran militantes del Movimiento de Acción Popular Unitaria (MAPU); Federico Schopf, Hernán Loyola, Waldo Rojas militantes del PC; Enrique Lihn, simpatizante del PC; Hernán Valdés se declaraba de izquierda, pero independiente y Cristián Huneeus era cercano a la Democracia Cristiana.

El Taller no se definió como un espacio de debate político, su intención era constituirse en un lugar de discusión literaria. Las obras se presentaban semanalmente, las que eran revisadas y criticadas por los asistentes. Hubo un interés por la teoría que quedó registrado en la discusión que presentaron Enrique Lihn y Waldo Rojas sobre el libro Los gatos de Roland Barthes ${ }^{25}$, sin embargo fue una iniciativa de índole personal.

Asistían al taller escritores que estaban en proceso de formación, los que recibían una beca de manutención, pero también literatos de trayectoria nacional y latinoamericana como Mario Benedetti, Ernesto Cardenal y Antonio Cisneros.

La existencia del Taller en el marco del triunfo de la Unidad Popular, hizo que inevitablemente se incluyeran temas políticos. Si bien el interés estaba puesto en desarrollar un taller literario, Hernán Valdés explica que en éste "por primera vez, se planteó la situación del artista y, en especial del escritor, en el nuevo proceso político, de un modo coherente con las necesidades culturales objetivas del pueblo"26. Sostuvo, que, a partir de ello, definieron su participación en el gobierno de Salvador Allende como disparadores o instrumentalizadores de una nueva cultura, la que debía nacer desde el pueblo.

A nuestro parecer, el Taller de la Universidad Católica actuó como un espacio de sociabilidad intelectual, que permitió la reunión de escritores con una visión en común respecto cómo debía ser la cultura en la vía chilena al socialismo. Entendiendo sociabilidad intelectual como una práctica social que configura el espacio en el que se llevan a cabo las actividades de un grupo determinado, este espacio se consolidó como un lugar de comunicación social en una esfera pública determinada ${ }^{27}$, adquiriendo, en el caso de estos escritores, una connotación que iba más allá de la socialización, pues tuvieron la intención de influir en la formulación de la política cultural del gobierno de la Unidad Popular.

Así, el Taller de escritores de la Universidad Católica fue un espacio de encuentro, producción y circulación de ideas, que iban más allá de la literatura, conmovidas por el significado que estos escritores le otorgaron al gobierno de Salvador Allende.

\footnotetext{
25 Bianchi, op. cit., 212.

26 Hernán Valdés, “¿Prudencia o desorientación para formular las bases de una política cultural?”, Cuadernos de la Realidad Nacional, No8, Junio 1971, 255.

27 Pilar González, "Sociabilidad y opinión pública en Buenos Aires (1821-1852)”, Historia Contemporánea, N² 27, $2003,664$.
} 


\section{Una política cultural para la Unidad Popular.}

El documento titulado Política Cultural: por la creación de una cultura nacional y popular, fue firmado por los escritores Antonio Skarmeta, Poli Délano, Ariel Dorfman, Hernán Valdés, Enrique Lihn, Federico Schopf, Martín Cerda, Waldo Rojas, Germán Marín, Cristián Huneeus y Jorge Edwards y publicado en la edición número 8 de Cormorán, en diciembre de 1970, siendo el último número de la revista que dirigía Enrique Lihn.

Cormorán era una revista literaria y cultural, que contó con ocho publicaciones entre agosto de 1969 y diciembre de 1970. Con un enfoque crítico, cuestionó la dependencia y subdesarrollo cultural del país desde una posición marxista heterodoxa, construyó un discurso sobre la necesidad de liberar la cultura nacional y latinoamericana del imperialismo, planteando la urgencia del compromiso político del escritor con los cambios que se vislumbraban ante las posibilidades de triunfo de la Unidad Popular, estimulando la participación de los intelectuales en la discusión sobre la cultura en la transición al socialismo.

El grupo de literatos, firmó el documento bajo el autodenominado Taller de escritores de la Unidad Popular, al respecto Enrique Lihn señaló que "con la aprobación de militantes de un partido de izquierda, se cometió, presumiblemente, el error táctico -imputable al entusiasmo generalizado- de englobar a un grupo poco numeroso de individuos, bajo el rótulo de «Taller de escritores de la Unidad Populan»" 28 . Si bien para Lihn lo del rotulo pudo haber sido un error, desde la perspectiva histórica, nos parece que la adopción de ese nombre manifiesta la adscripción de estos escritores al proyecto socialista y la definición de su accionar intelectual, con el que pretendían aportar a la construcción de una «nueva cultura». Aquello, queda en evidencia en la editorial de la edición número 8 de la revista Cormorán en la que se publicó la propuesta cultural

El triunfo electoral obtenido el 4 de septiembre último por el doctor Salvador Allende, representante de los partidos y movimientos de la Unidad Popular, abre al país posibilidades inéditas en su desarrollo político y cultural.

(...) En este sentido, el proceso social que se iniciará a partir de las transformaciones estructurales programadas por el gobierno de la Unidad Popular, obliga a asumir las metas que una concepción diferente de la cultura deberá adoptar para colaborar en la tarea común de crear una sociedad nueva. Tal como ha sido señalado en cuanto que el trabajo humano será considerado como el más alto valor, la voluntad de afirmación e independencia nacional serán expresadas y una visión crítica de la realidad será a la vez conformada, se delinea una suerte de humanismo integral para quienes debemos ser partícipes como trabajadores de la cultura en este reto contra las estructura obsoletas cuya trascendencia dependerá desde ahora del esfuerzo, lucidez y honestidad de cada uno de nosotros ${ }^{29}$.

A partir de ello, es posible sostener que este grupo de escritores se sintió llamado a iniciar un debate acerca de la cultura, compartiendo el diagnóstico de la revista Cormorán.

Respecto del error sobre la denominación del Taller de la Unidad Popular, Enrique Lihn sostenía hacia 1988, que el apelativo tenía relación con el reciente triunfo de la coalición de izquierda, que causó "fervor y entusiasmo por parte, por lo menos, de un porcentaje grande de las personas que estaban ahí [en el Taller], pero no todos, pues había gente que no quería saber nada con política" 30 . Es importante tener en cuenta en este trabajo, que estamos examinando la visión de un grupo de escritores que no representaba, necesariamente, el posicionamiento del Taller de escritores de la Universidad Católica, ya que como se indicó en el apartado anterior, dicho taller tenía una connotación literaria que, por la

\footnotetext{
28 Enrique Lihn, "Política y cultura en una etapa de transición al socialismo", VV.AA, La cultura en la vía cbilena al socialismo, Santiago, Editorial Universitaria, 1971, 26.

${ }^{29}$ Editorial, Cormorán, N8, diciembre 1970, 2

30 Bianchi, op. cit., 215.
} 
contingencia del triunfo de la Unidad Popular, un grupo de ellos se sintieron llamados a proponer ideas en torno a la cultura, como una muestra de adhesión al gobierno que asumía.

A lo largo de la propuesta cultural, es posible encontrar una serie de premisas y visiones acerca de la construcción de una «nueva cultura». Los escritores planteaban, en primer lugar, la necesidad de establecer un marco normativo, que guiara la transformación de la cultura en el país

Estimamos que el fin de toda política cultural genuina debe ser el de alcanzar nuestra madurez nacional, realizando en ello el sentido profundo de nuestra historia desde sus primeras manifestaciones propias. Así la transformación de nuestra sociedad debe darse en términos de una comprensión de nuestro ser que haga posible el proceso y que recoja sus experiencias. De otro modo, incluso el intento mismo de transformación de nuestras estructuras económicas estará viciado ${ }^{31}$.

Para el desarrollo de una «nueva cultura», los escritores indicaron que en primer lugar debía combatirse la "penetración cultural de las empresas multinacionales, dependientes del imperialismo norteamericano, como asimismo las instituciones educacionales y culturales amparadas por éste en todo el mundo" 32 , pues para ellos la burguesía nacional había adoptado un modelo foráneo que proporcionaba un estímulo insuficiente a la creación de una cultura nacional.

Estado Unidos, desde la década del cuarenta, había impulsado en América Latina políticas de cooperación y fomento cultural, por medio de becas y oportunidades profesionales a través de fundaciones como Ford y Rockefeller, cuya finalidad era consolidar su zona de influencia tras el término de la Segunda Guerra Mundial, posteriormente, amplió este objetivo con la exportación del modelo de la comunicación de masas y cultura de consumo.

En ese escenario, los escritores firmantes de la propuesta señalaban que "el caso de burguesías dependientes, como la nuestra, asimiladas a las superestructuras culturales foráneas, han invalidado todo proceso cultural autónomo que arranque de las bases sociales, radicalizando el divorcio entre sociedad y cultura" 33 .

La cultura de masas, a juicio de estos actores, había provocado una reverencia a las formas de contenidos importados, receptividad a los valores extranjeros y utilización de una subcultura extraña (comics, cine-novela, seriales de televisión), cuya consecuencia era el desarrollo de una cultura subdesarrollada que impedían la organización y coordinación de una institucionalización cultural que cumpliera con su función social. Por ello la propuesta apuntaba a establecer mecanismos de independencia respecto del modelo estadounidense.

Se aprecia en la propuesta cultural, un diagnóstico sobre la situación cultural, en la que se señala la existencia de una relación de dependencia, entre la burguesía nacional y el capital extranjero, lo que provocaba que la sociedad abandonara la producción de expresiones culturales y se llevara a cabo un proceso de trasvasije de los modelos extranjeros, anulando la cultura nacional. El análisis de este grupo sostiene que

Vemos como el subdesarrollo se genera a partir de la relación de dependencia global de nuestra sociedad con respecto al imperialismo, la cual condicionó en el interior del país una visión y acción deformantes en las clases que hasta ahora han detentado el poder, entendiendo y utilizando la necesidad creadora del hombre en beneficio de su propio status ${ }^{34}$.

A partir de ello, visualizamos en la propuesta la antinomia dependencia-liberación, la que expresaba el diagnóstico de la realidad cultural y, a la vez, establecía una proyección en torno al camino a seguir

\footnotetext{
31 "Política Cultural", Cormorán, Nº, Diciembre 1970, 7.

32 Ibíd.

33“"Política Cultural", Cormorán, N8, Diciembre 1970, 7.

${ }^{34}$ Ibíd.
} 
La liberación de nuestras posibilidades como pueblo, hasta hoy marginado, sólo será posible si la comunidad se redefine, busca expresarse y se da al esfuerzo constante de crear las imágenes de sí misma que la historia reclama. Superar el subdesarrollo y la dependencia es a la vez una acción cultural. Y con el triunfo de la Unidad Popular se abre la primera oportunidad para llevar a cabo esta $\operatorname{tarea}^{35}$.

En este escenario, el papel que les correspondía a los intelectuales y artistas en este proyecto, a juicio de este grupo de escritores, era

Ser el de vanguardia, el de crítico, el de celador. ¿Cómo pueden cumplir dicho papel en la práctica? (...) sólo puede cumplirse mediante la incorporación de los artistas e intelectuales a ciertos y determinados organismo de poder, siempre que tales organismos se estructuren bajo una genuina inspiración y cuenten con un apoyo oficial que comprenda la auténtica y vital función de la cultura ${ }^{36}$.

Cuando señalan el apelativo de vanguardia, este grupo de escritores asume que artistas e intelectuales tenían un complejo papel orientador, el que expresaron como "el de vanguardia del pensamiento; crítico permanente de un presente conflictivo; el de conciencia vigilante de los hitos alcanzados y de las proyecciones auténticas que vayan resultando como conclusiones. Si estos tres momentos pueden diferenciarse, no por ello dejan de conformar una unidad inseparable: la del trabajo intelectual" 37 .

En términos prácticos, los escritores señalaban que debían crearse una institución central que podía llamarse Instituto Nacional de Cultura o Corporación de Fomento a la Cultura. Esta, a su parecer, debía partir sus tareas con un catastro nacional de medios de comunicación e instituciones culturales existentes y presentar al gobierno un plan de reorientación y reorganización, siguiendo las ideas presentadas en la propuesta. Además, la Corporación debería crear el Instituto del Libro y Publicaciones, cuyas características e indicaciones fueron presentadas en un documento anexo a la propuesta, en la edición número ocho de la revista Cormorán. Los escritores serían partícipes de la construcción de ese Instituto como un aporte a la Corporación de Fomento a la Cultura.

La propuesta define cómo construir la «nueva cultura» estableciendo una estructura, pero en ningún momento señala cómo vincular la cultura popular ligada a las tradiciones o la que estaba surgiendo a través de movimientos como la Nueva Canción Chilena, el muralismo de la Brigada Ramona Parra o el teatro popular. Se infiere, que el documento se centró en la formulación de una política pública y la definición del intelectual como vanguardia, sin considerar los mecanismos por los cuales se incluiría al pueblo en estas transformaciones.

\section{Profundización de la propuesta: La cultura en la vía chilena al socialismo.}

La propuesta cultural presentada por el grupo de escritores, los situó como actores críticos del proyecto cultural de la vía chilena al socialismo, ya que la redacción del documento estaba al margen de cualquier partido político, lo cual de alguna manera era problemático, ya que como indicamos anteriormente, los firmantes militaban en los partidos que daban vida a la Unidad Popular. Enrique Lihn sostuvo, en conversación con Soledad Bianchi, que el documento

Es de triste memoria porque fue inmediatamente objetado por el Partido Socialista y el Partido Comunista, qué sé yo, que consideraron como una muestra de oportunismo que gente muy heterogénea escribiera un documento de apoyo al gobierno, porque allí uno de los redactores era

35“Política Cultural", Cormorán, No8, Diciembre 1970, 7.

36"Política Cultural", Cormorán, N8, Diciembre 1970, 8.

37 "Política Cultural”, Cormorán, No8, Diciembre 1970, 7. 
Cristián Huneeus que había votado por Tomic, así son las cuestiones políticas, las dramatizaciones y las exageraciones ridículas políticas ${ }^{38}$.

El poeta se refiere a una serie de cuestionamientos que recibió la propuesta cultural, entre las cuales se encuentra la expresada en el libro La revolución chilena y los problemas de la cultura de la editorial Horizonte (1971), que reunía las exposiciones que presentaron el encargado cultural del PC, Carlos Maldonado y el escritor comunista Volodia Teitelboim en la Asamblea de trabajadores de la cultura, desarrollada el 11 y 12 de septiembre de 1971.

Carlos Maldonado expresó en su elocución, que "todavía hay muchos profesionales de la cultura que sólo piensan que ha llegado la hora de la justicia para los postergados, y esperan sentados que sus libros se publiquen, que sus obras se vendan o se les ofrezca un cargo, sintiéndose al margen de un gobierno al que ellos mismos pertenecen" 39 . Agregando, que los intelectuales en el gobierno de la Unidad Popular tenían "una tarea depuradora de alta responsabilidad, que principalmente atañe a la crítica; pero no en una función supervisora de la cultura, sino más bien de estímulo para los creadores, de esclarecimiento ideológico y de educación para las grandes masas" ${ }^{40}$.

La afirmación del encargado cultural del PC, se ajustaba al programa de la Unidad Popular publicado en diciembre de 1969-, que posicionaba a los intelectuales y artistas como "luchadores contra las deformaciones culturales de la sociedad capitalista, los que llevaban los frutos de su creación a los trabajadores y tendrían en la nueva sociedad un lugar de vanguardia para continuar con su acción" 41.

Si bien el programa asignaba un papel de vanguardia a los intelectuales, Carlos Maldonado era bastante crítico de esa definición, planteando que en el proceso de las transformaciones culturales "no caben ni el estrecho "dirigismo" que lo sectarice, como tampoco una tal apertura que lo suma en un caotismo sin brújula" 42 . Para el encargado cultural del PC, se debía involucrar activamente al pueblo en el proceso de transformación, afirmando que dicho proceso "no es una tarea exclusiva de los artistas e intelectuales sino de todo el pueblo"43.

Sin quedar ajenos a la crítica esgrimida por Maldonado, algunos de los escritores firmantes de la propuesta profundizaron las ideas desarrolladas en la propuesta cultural en el libro La cultura en la vía chilena al socialismo, publicado en diciembre de 1971 por la Editorial Universitaria, dentro de la colección Cormorán. El libro chileno de bolsillo. Los autores fueron Enrique Lihn, Hernán Valdés, Cristián Huneeus, Carlos Ossa y Mauricio Wacquez -los dos últimos no aparecen como firmantes del documento Política Cultural-. Si bien este libro representa el pensamiento de tres de los 12 integrantes del Taller que firmaron el documento antes revisado, tuvo la intención de contribuir al debate sobre la política popular y como señala Enrique Lihn, "ahí algunos de los que quedamos con sangre en el ojo lo escribimos, éramos los menos" 44 .

Respecto a la dispersión de los escritores del Taller, frente a la publicación de este libro, el mismo Lihn señala, que los literatos no quisieron participar de una actividad que no consultaba la opinión de los partidos, señalando los casos de Antonio Skarmeta, Ariel Dorfman (militantes del MAPU) y Federico Schopf (militante comunista) ${ }^{45}$. Además, agrega otro dato importante a tener en cuenta, la composición del Taller, en términos de heterogeneidad política, manifestaba las diversas posturas respecto a la política cultural del gobierno. Por una parte, se encontraba el grupo de participó en la publicación del libro La cultura en la vía chilena al socialismo, que en cierta manera profundizaba las ideas expresadas en la propuesta

\footnotetext{
38 Bianchi, op, cit., 214.

${ }^{39}$ Carlos Maldonado, La revolución chilena y los problemas de la cultura, Santiago, Horizonte, 1971, 14.

40Maldonado, op, cit., 15.

41"Programa básico de gobierno de la Unidad Popular", Candidatura presidencial de Salvador Allende, 17 de diciembre de 1969, 27-28.

42 Maldonado, op, cit., 8

43 Maldonado, op, cit., 10

44 Bianchi, op. cit., 214.

45 Bianchi, op. cit., 215.
} 
cultural y, por otra parte, existía otro grupo, compuesto por Skarmeta, Dorfman y Schopf, que desde su militancia política tomaron una posición a favor de desarrollar una revolución cultural, emulando la política que estaba llevando a cabo el régimen cubano desde el año 1968.

Se entiende, por lo tanto, que este libro no representa la posición del Taller, sino la de un grupo que, desde su compromiso con el proyecto de la vía chilena al socialismo, creía necesario profundizar la discusión sobre la cultura. En la nota de los autores del libro, se señalan que

Trátese, evidentemente, de nociones polémicas que, en rigor, son proposiciones para una más amplia discusión ulterior. Ninguno de los autores pretende haber agotado el tema; por el contrario, se advierte a lo lardo de los trabajos que el debate recién comienza. En un año de gobierno de la Unidad Popular han aparecido escasos documentos que ejemplifiquen una toma de posición frente a los problemas culturales. Sólo se puede hablar de dos textos coherentes: el que fue elaborado por el Comité de la Unidad Popular del Taller de Escritores de la Universidad Católica y el que leyó Carlos Maldonado en el Congreso de Intelectuales Comunistas. Por eso, aunque algunas de estas formulaciones pudieran parecer incompletas, la urgencia de proponer el debate aludido en un nivel serio y consistente justifica su edición en un volumen ${ }^{46}$.

El libro contiene 5 artículos, de los cuales revisaremos los que corresponden a los escritores que firmaron el documento Política Cultural, estos son el de Enrique Lihn "Política y cultura en una etapa de transición al socialismo"; Hernán Valdés, "Ante la especulación y el divisionismo. Por una práctica cultural comprometida" y el de Cristián Huneeus, "El intelectual en su contribución al socialismo".

Enrique Lihn en su artículo, indica que el documento Política Cultural, firmado por el Taller de escritores de la Unidad Popular, fue "calificado como antimarxista; en nombre de un principio enunciado por Marx en su Contribución a la crítica de la Economía Política, principio verdaderamente aplicado a la fuerza, en este caso: «No es la conciencia de los hombres lo que determina su ser, sino, por el contrario, su ser social es el que determina su conciencia» ${ }^{47}$.

El poeta justificaba en este artículo, que la propuesta buscaban resolver el papel del intelectual en una etapa de transición al socialismo, por lo tanto el documento tenía un acuerdo tácito con el principio que se le acusaba traicionar, ya que apelaba a la transformación social recogiendo la experiencia del pueblo ${ }^{48}$. Para Lihn, la crítica comunista tenía un fuerte componente de ortodoxia marxista, ya que entendía a "la conciencia como un reflejo pasivo de dicho ser, y a la infraestructura, como un sólido bloque refractario a todo, sobre el cual se constituye el mundo cultural, reducido a la mera expresión de la base económica"49.

Enrique Lihn, citando al filósofo marxista checoeslovaco Karel Kosík, manifestaba que "si partimos de la praxis humana como de la realidad social fundamental, descubrimos de nuevo que también en la conciencia humana sobre la base de la práctica y en unidad indisoluble, se forman dos funciones esenciales: la conciencia humana al mismo tiempo registra y proyecta, verifica y planea: o sea es a la vez reflejo y proyecto 50 .

Kosík planteó que el arte tiene una función social: crear y reproducir la realidad, en una dialéctica donde el autor es creador y organizador. Con ello buscaba reivindicar las artes y la cultura, defendiendo la autonomía del autor y la de su obra oponiéndose a "su identificación heterónoma con cualesquiera poderes fácticos de que se tratase, fueran estos políticos o académicos" 51 . El filósofo cuestionaba el

46 VV.AA. La cultura en la vía chilena al socialismo, Santiago, Editorial Universitaria, 1971, 11.

${ }^{47}$ Lihn, op, cit., 26. El poeta indica en la entrevista dada a Soledad Bianchi en el libro Memoria: modelo para armar, que la crítica fue publicada en el diario El Siglo, sin mencionar mayores datos para su ubicación.

${ }^{48}$ Lihn, op, cit., 27.

${ }^{49}$ Ibíd.

50Lihn, op, cit., 27-28.El autor cita a Karel Kosík, Dialéctica de lo concreto, México, Grijalbo, 1967,66. Las Cursivas son del autor https://marxismocritico.files.wordpress.com/2012/05/dialecticadeloconcreto.pdf

51 Jorgi Magnet, "Karel Kosík, marxismo y heideggerianismo en los albores de la Primavera de Praga”, Revista Laguna, N³5, diciembre 2014, 113.

https://riull.ull.es/xmlui/bitstream/handle/915/4319/L $35 \% 282014 \% 29$ 06.pdf?sequence=1\&isAllowed $=\mathrm{y}$ 
realismo socialista, que indicaba que el arte debía estar al servicio de la transformación ideológica del pueblo y por lo tanto, la creación debía obedecer los lineamientos burocráticos del régimen en el que estaba inserto el artista.

Los planteamientos de Kosík, recogidos por Lihn, fueron desarrollados en medio del proceso de des-estalinización que experimentó la órbita soviética a partir de la muerte de Stalin en marzo de 1953 y el pronunciamiento del discurso secreto de Jrushchov en el XX Congreso del Partido Comunista de la Unión Soviética en febrero de 1956. Mientras que, en el plano local, fueron enunciados en los años en que el líder comunista checoslovaco Alexander Dubček formuló el programa de reformas que buscaba construir un "socialismo de rostro humano" dentro de lo que se conoció como Primavera de Praga, experiencia resistida por el comunismo checoslovaco y el régimen soviético. La URSS, para contener y mantener bajo su zona de influencia a Checoslovaquia, decidió invadir al país el 20 de agosto de 1968, aplacando el proyecto reformador.

Parte del mundo intelectual cuestionó y criticó esta acción, propiciando el desarrollo de nuevos marcos interpretativos de la realidad, anclados en lecturas de Marx que iban más allá del determinismo económico. En ese sentido, Karel Kosík sostenía que el marxismo

\begin{abstract}
No es un materialismo mecanicista que intente reducir la conciencia social, la filosofía y el arte a las "condiciones económicas", y cuya actividad analítica se base, por tanto, en el descubrimiento del núcleo terreno de las formas espirituales. Por el contrario, la dialéctica materialista demuestra cómo el sujeto concretamente histórico crea, partiendo de su propia base económica material, las ideas correspondientes y todo un conjunto de formas de conciencia. La conciencia no es reducida a las condiciones dadas; el centro de atención lo ocupa un proceso, en el cual el sujeto concreto produce $y$ reproduce la realidad social, al mismo tiempo que es producido y reproducido históricamente en ella ${ }^{52}$.
\end{abstract}

La adscripción a este marxismo por parte de Enrique Lihn, pone en evidencia la recepción y circulación de un marxismo que se distanciaba del eje intelectual soviético y esquematismo del PC chileno.

La postura de estos literatos se enmarcó en la idea de que el hombre percibe y construye su realidad, por lo tanto la política cultural de la Unidad Popular debía estimular la creación del pueblo, establecer una alianza con la pequeña burguesía y forjar instituciones que se hicieran cargo de las transformaciones, como por ejemplo la Corporación de Fomento a la Cultura, donde los intelectuales debían ocupar puestos de dirección, para que todas las fuerzas reunidas en el proyecto socialista construyeran la «nueva cultura».

El gobierno, hacia fines de 1971, aún no había definido de manera clara cuál sería su política cultural, lo que para Hernán Valdés se debía a dos situaciones estructurales y políticas: primero, la designación exclusiva de representantes de los partidos en responsabilidades directivas y ejecutivas y segundo, la creación y fomento de una penosa y artificial división entre los intelectuales y creadores culturales, que sitúa el quehacer en el terreno de la discusión y no en el de la práctica ${ }^{53}$.

Cristián Huneeus explicaba que, a pesar de las diferencias entre los intelectuales y el PC, el objetivo era contribuir a la creación de una cultura nacional y popular, en una etapa que consideraba como transición al socialismo, la que requería del trabajo de intelectuales y personeros políticos. Huneeus, manifestaba que "para no apartarse de la realidad concreta, es preciso validar con firmeza el papel del intelectual, no sólo en la transición al socialismo sino también, y lo habremos de probar a su debido tiempo, en el estado socialista" ${ }^{44}$. Para argumentar esta afirmación, el escritor citó el trabajo del filósofo polaco Leszek Kolakowski, titulado Los intelectuales y el movimiento comunista.

\footnotetext{
52Karel Kosík, op, cit., 64.

53Hernán Valdés, “Ante la especulación y el divisionismo: por una práctica cultural comprometida”, VV.AA, La cultura en la vía chilena al socialismo, Santiago, Editorial Universitaria, 1971, 81-82.

${ }^{54}$ Cristián Huneeus, "El intelectual en su contribución al socialismo", VV.AA. La cultura en la vía cbilena al socialismo, Santiago, Editorial Universitaria, 94.
} 
Kolakowski fue un importante filósofo marxista polaco, enviado por el gobierno polaco a Moscú en 1956 para seguir cursos de formación como dirigente, pero una vez allí comenzó a desarrollar una postura crítica sobre el régimen soviético y el de su país, lo que provocó su expulsión de Polonia hacia 1968 y exilio en Canadá. A partir de ese momento, su posición política convergió hacia el revisionismo del marxismo, transformándose en uno de los pilares intelectuales del movimiento obrero Solidaridad, dirigido por Lech Walesa, cuyo propósito era en principio lograr la libertad sindical, para posteriormente luchar por la democratización de Polonia. Su distanciamiento con el régimen soviético y el estalinismo queda en evidencia cuando establece el lugar que deben ocupar los intelectuales en los procesos revolucionarios.

Kolakowski, en el texto citado por Huneeus, indicó "que el movimiento que se propone como meta política destruir el poder de la burguesía y modificar todos los ámbitos de la vida humana no puede avanzar sin la teoría" ${ }^{5}$. Esto asignaba a los escritores un papel fundamental respecto de la discusión cultural, pues no se trataba sólo de mediar entre la política cultural y el pueblo, también le correspondía reflexionar críticamente sobre el proceso. Para reafirmar esta postura, Huneeus vuelve a citar Kolakowski: "la intelectualidad es la auténtica creadora de la cultura socialista en sus diversas formas, sobre todo en sus formas intelectuales y artísticas" 56 .

Por lo tanto, se puede argüir, que la distancia entre estos escritores y el PC respondió a los cuestionamientos sobre el papel de los intelectuales y su participación en el terreno de las políticas públicas. Aquello, como problema histórico, remite a la figura del intelectual y su vínculo con el campo político, que en este caso y contexto se vio expresado en el ingreso de los escritores al debate sobre la política cultural y su propia definición como vanguardia.

\section{Tensiones en la política cultural: ¿frente único o revolución cultural?}

La lucha contra la dependencia y subdesarrollo era, para estos literatos, la primera etapa para la instauración de una «nueva cultura», donde debía existir un compromiso de los intelectuales con el pueblo. Hernán Valdés planteaba, que "dada la estructuración de la sociedad chilena, no puede pensarse en una acción cultural uniforme; ésta debe tener la suficiente versatilidad de proposiciones, evidentemente dentro de una ideología de liberación, como para interesarse y comprometer a todos los sectores progresistas de la población" 57 .

Para Valdés, era necesario construir una política cultural en la que participaran vastos sectores sociales, incluyendo a la pequeña burguesía, lo que reafirmaba Enrique Lihn, quien indicaba que el documento Política Cultural establecía el "proyecto de una democracia socialista por cristalizarse en Chile a través de una gradual polarización de los sectores sociales, destinada a ampliar la base política de la Unidad Popular, antes de proceder a la división de dos bloques" 58 . Lihn, Valdés y Huneeus consideraban los primeros años de la Unidad Popular como un tiempo preparatorio, donde en primer lugar debía llevarse a cabo un programa de educación que incluyera una campaña de alfabetización -en el censo de 1970 se registró un 10,20\% de analfabetismo a nivel nacional ${ }^{59}$ - y ampliación del acceso a los niveles de enseñanza básica, secundaria y universitaria para balancear las condiciones culturales del pueblo; posterior a ello, se debía proceder al establecimiento de una lucha ideológica entre la burguesía y el pueblo.

\footnotetext{
55Huneeus, op, cit., 95.

56Ibíd.

${ }^{57}$ Valdés, op, cit., 80 .

${ }^{58} \mathrm{Lihn}$, op, cit., 68.

${ }^{59}$ Información recogida del Instituto Nacional de Estadísticas (INE), Informe XIV Censo de la población y III de vivienda, 1970, 40 .

http://web.archive.org/web/20130614205242/http://www.ine.cl/canales/usuarios/cedoc online/censos/pdf/censo 1970.p $\underline{\mathrm{df}}$
} 
Este objetivo, implicaba adecuar el proyecto cultural al contexto nacional para establecer una base común de entendimiento y conocimiento. Para ello consideraban necesario construir un «Frente Único» que expresara una alianza entre el mundo popular y la pequeña burguesía, donde los intelectuales actuarían como agentes vinculantes entre estos dos sectores. No obstante, esta idea fue enfrentada por el PC e intelectuales que se sentían atraídos por la idea de la «revolución cultural», siguiendo el ejemplo cubano.

El cambio en la política cultural en la isla, estuvo marcado por la idea de que los intelectuales se involucraran directamente en el proceso revolucionario, es decir, que su producción -literaria y críticaestuviera al servicio de la Revolución. El cambio de los objetivos culturales estuvo marcado por el caso Padilla, que refiere al poeta Heberto Padilla, quien a juicio del aparato burocrático cubano se mostró crítico de la Revolución a través de obras como Fuera de juego publicada en 1968 y Provocaciones, con la que obtuvo el premio de la Unión Nacional de Escritores y Artistas de Cuba (UNEAC) en 1971, otorgado por un jurado internacional y que fue presentado en un recital organizado por dicha entidad.

Tras la presentación de Provocaciones, el 20 de marzo de 1971, el poeta fue detenido por organismos de seguridad del régimen, tras un historial de intervenciones que contravenían la postura que debían tener los intelectuales frente a la Revolución. Luego de una larga detención, Padilla aceptó los cargos y fue obligado a redactar una autocrítica, donde "reconocía" sus errores, la que debió memorizar y exponer frente a los miembros más importantes de la UNEAC, posterior a ello se exilió en Estados Unidos.

Este caso fue un verdadero parte aguas en la intelectualidad latinoamericana y europea. Escritores que habían apoyado a la Revolución consideraban que con este accionar el régimen cuestionaba la independencia de creación y pensamiento de los intelectuales, lo que quedó plasmado en una declaración que fue publicada en el semanario Marcha de Uruguay, en la edición del 16 de abril de 1971. Entre los firmantes se encontraban Simone de Beauvoir, Ítalo Calvino, Julio Cortázar, Carlos Fuentes, Gabriel García Márquez, Octavio Paz, Rossana Rosanda, Jean Paul Sartre y Mario Vargas Llosa, quienes señalaban que

(...) En momentos en que la instauración de un gobierno socialista en Chile y la nueva situación en Perú y Bolivia facilitan la ruptura con el bloque criminal impuesto a Cuba por el imperialismo norteamericano, el empleo de métodos represivos contra los intelectuales y escritores que han ejercido el derecho de crítica a la revolución, no puede más que provocar una repercusión profundamente negativa entre las fuerzas antiimperialistas de todo el mundo, y más concretamente de América Latina, para la que la Revolución Cubana constituye un símbolo y un estandarte ${ }^{60}$.

Con estas palabras, los intelectuales tomaban partido en el bullado caso Padilla y expresando su descontento frente a lo que consideraban como un atentado contra el derecho a crítica. Con un objetivo similar, Enrique Lihn envió una carta abierta a su amigo Heberto Padilla, la que no fue publicada en medios chilenos. Según el poeta, los motivos de tal decisión, era que esos medios querían evitar tener problemas con Cuba ${ }^{61}$. Lihn envió su carta a Ángel Rama, director de Marcha, quien la publicó en la misma edición que difundió la autocrítica de Heberto Padilla.

En la carta, es posible observar los puntos de crítica de Lihn respecto del caso de su amigo y sobre el tratamiento que estaba dando el régimen cubano a los intelectuales:

En sus Palabras a los intelectuales, la fórmula de Fidel Castro: todo con la revolución, nada contra ella, daba pauta de lo que el movimiento revolucionario podía permitirse, en materia de creación artístico-cultural, como libertad de expresión. Sólo que, la medida de ésta no fue ni podía ser determinada. "Una revolución — escribieron Paul Sweezy y Leo Huberman, respecto de la cubanaes un proceso, no un suceso, se desenvuelve por etapas y fases. No se detiene nunca; lo que hoy es

60 "Sobre el caso Padilla", Marcha N 1539, Montevideo, 16 de abril de 1971, 29.

${ }^{61}$ Bianchi, op, cit. 215. 
cierto de la revolución, mañana puede ser incierto o viceversa". Otro peligro que debe ser sorteado, por el esfuerzo inteligente de la vanguardia revolucionaria ${ }^{62}$.

Lihn termina la carta manifestando su visión respecto del papel del escritor en un proceso revolucionario:

El "impertinente Padilla", como alguien te llamaba en La Habana, podía permitirse acaso, "salirse de madre", hablando hasta por los codos, de este mundo y del otro. Así, supongo, te creaste enemistades, dentro y fuera de tu país. Pero esas "descargas" no eran, en modo alguno, productos, como dijo Verde Olivo, de la necesidad de satisfacer una vanidad, haciéndote de una "cartelito en el extranjero". Esos excesos verbales comprendían el repaso de una cultura poco común tanto en Latinoamérica como en el mundo; se deslizaban por la poesía y la literatura, en varios idiomas; apuntaban al análisis y la controversia; incluían el amor a Cuba, el odio razonado a sus enemigos y también, claro está, la crítica merecida a sus amigos. Así te recuerdo yo con verdadera amistad ${ }^{63}$.

En Chile, un grupo de literatos e intelectuales adherentes a la Revolución, publicaron el documento Declaración Chilena -entre ellos Federico Schopf, uno de los escritores que firmaron la propuesta cultural-. La declaración cuestionó el accionar de Padilla y estuvo de acuerdo con el proceder del régimen:

Rechazamos de manera terminante la existencia de castas privilegiadas de intelectuales que se adjudican el monopolio de la verdad o de la conciencia crítica, situándose en la práctica como árbitros o pasivos espectadores de la lucha que cotidianamente libran sus pueblos por eliminar la barreras de la opresión (...) Creemos que no puede haber individualidades que se autoerijan en jueces de la historia; de existir una conciencia crítica ella es parte de la comunidad, es el pueblo que revolucionariamente busca su destino ${ }^{64}$.

Esta declaración, pone en evidencia que, entre los intelectuales chilenos, adherentes al gobierno de la Unidad Popular no había una posición respecto a la política cultural y el papel de los intelectuales en ésta. De hecho Enrique Lihn, señala en la entrevista realizada por Soledad Bianchi, que a los escritores militantes "los pusieron en cintura en los partidos a los que entraron como Skármeta, Dorfman o el mismo Federico Schopf, quienes se pusieron en una posición muy radical, a favor de la Revolución Cubana, y de la revolución cultural cubana" 65 .

Respecto a la revolución cultural cubana, su objetivo era estructurar una cohesión ideológica del cuerpo social, sacrificando escuelas, estilos, géneros, estéticas ante la urgencia de consolidar nuevas relaciones de las fuerzas productivas ${ }^{66}$. Ángel Rama, señalaba que

A partir de estos presupuestos debe encararse la ruptura fatal del frente único con los escritores progresistas de los países burgueses y la evolución acelerada del grupo intelectual cubano, que habrá de ir erradicando sus orígenes burgueses todavía persistentes, individualistas, inclinados al uso del falso concepto de la "conciencia crítica" para integrarse a las tareas que les incumbe en la sociedad socialista homogénea ${ }^{67}$.

El caso Padilla puso en aviso a algunos escritores chilenos, que inmersos en el proyecto de la Unidad Popular no estaban de acuerdo con una política cultural que intentaba controlar la obra de los

\footnotetext{
62 "I. Carta de Enrique Lihn", Marcha N 1541, Montevideo, 30 de abril de 1971, 28. La frase en negrita es del autor.

63 Ibid.

64“Declaración chilena”, Ahora N¹0, 22 de junio 1971, Enrique Lihn, op, cit., 43.

${ }^{65}$ Bianchi, op, cit., 215.

66Ángel Rama, "Nueva política cultural cubana. Una autocrítica”, Marcha N¹549, 25 de junio 1971, 12

${ }^{67}$ Ibíd.
} 
escritores. Es por ello que el libro La cultura en la vía chilena al socialismo se presentó a contracorriente de lo que estaba pensando el PC, pues sus ideas velaban por la libertad de su trabajo, el desarrollo de una política cultural en comunión con el gobierno y los procesos creativos del pueblo, dentro de lo que consideraban como una etapa de transición que requería la conformación de un «Frente Único».

Ante la idea de una «revolución cultural», Cristián Huneeus manifestaba que el aparato burocrático se "apoderaría de toda la actividad intelectual, desvalorizaría y violentaría las autonomías relativas de sus diversas esferas, retrotrayendo el nivel de la vida moral y material a un estado primario"68. Para el escritor, este tipo de política decantaba en un totalitarismo ejercido por una burocracia en nombre del arte, la teoría, la economía y la vida misma, que restaba posibilidades de creación y reflexión al pueblo y a los intelectuales. Mientras que para Hernán Valdés la postura del PC se sostenía "en el concepto proestalinista de la acción cultural, establecida burocráticamente y ejercida por delegados que representan el pensamiento y sensibilidad populares" ${ }^{69}$, que invalidaba la participación de escritores, intelectuales, artistas y el pueblo en la formulación y conducción de la política cultural.

La idea de la «revolución cultural» comenzó tener fuerza en el PC a partir de la Asamblea de trabajadores de la cultura. Si bien Carlos Maldonado no refiere directamente al desarrollo de una política de ese tipo, lo que si queda claro es la visión de una política cultural encabezada por el pueblo, desligada de la burguesía y la necesidad de construir una cultura de masas utilizando dispositivos como la televisión, revistas, editoriales y radios manejados por el Estado. Un ejemplo de ello fue la revista de las Juventudes Comunistas Ramona, la que se alejaba del canon de las publicaciones del PC como el periódico El Siglo y la revista Principios. El objetivo de la revista juvenil era "llegar a los jóvenes transmitiendo un mensaje político a través de una diagramación y recursos acordes a los gustos de la "cabrería", es decir, una especie de revista Ritmo, pero de izquierda" 70 , cumpliendo con lo que Carlos Maldonado proponía: "tenemos que ser capaces de crear una auténtica cultura de masas, utilizando incluso, en algunos casos los mismos vehículos formales [de la cultura burguesa]"'71.

Maldonado, entendía que cada actividad debía entenderse en términos de trabajo, ejemplo de ello fue la nominación Trabajador de la cultura que refería al intelectual y al artista que debía desempeñarse en un frente específico, por ejemplo en ChileFilms o la editorial Quimantú y, según Maldonado, el que "no laborara en un frente" debía readecuar su militancia partidaria de preferencia en industrias o poblaciones, esto porque debía producirse un "íntimo diálogo entre el pueblo y sus creadores, pero no sólo a través de sus obras o de encuentros ocasionales, sino en un conocimiento vital y diario"72. Así, la política cultural del PC posicionaba las funciones creadoras y organizadoras de los intelectuales y artistas en un contacto directo con el pueblo, asumiendo que dicho proceso sería eficaz para difundir el ideario cultu ral y lograr los objetivos impuestos por el gobierno socialista, lo que manifiesta, a nuestro parecer, una apuesta por la «revolución cultural».

La idea de situar al trabajador de la cultura en un frente de trabajo era igualar, en términos de nominación y prácticas, el trabajo manual e intelectual, lo que respondió, según Claudia Gilman al antiintelectualismo que a partir de 1970 recorrió a la izquierda latinoamericana motivado por la revolución cultural cubana ${ }^{73}$. Ante tales ideas, los escritores que hemos revisado en esta investigación, se vieron enfrentados a cuestionamientos sobre su función social, el lugar que les correspondía en el gobierno y su propia identidad, respecto a su producción crítica sobre el proyecto de la vía chilena al socialismo.

Para 1972, la idea del «Frente Único» había perdido fuerza frente a la necesidad de promover los cambios culturales que permitieran afianzar el programa de la Unidad Popular y fortificar la relación entre

${ }^{68}$ Huneeus, op, cit., 96.

${ }^{69}$ Valdés, op, cit., 264. Las cursivas son del autor.

${ }^{70}$ Carolina Fernández-Niño, "Revista Ramona (1971-1973) “... una revista lola que tomará los temas tangencialmente”. Rolando Álvarez, Manuel Loyola (Eds.), Un trébol de cuatro hojas. Las Juventudes Comunistas de Chile en el siglo XX, Santiago, Ariadna, 2014, 127.

${ }^{71}$ Maldonado, op, cit., 16.

${ }^{72}$ Maldonado, op, cit., 25.

${ }^{73}$ Gilman, op, cit., 186. 
el pueblo y el aparato gubernamental. Para ello, el gobierno estimuló el desarrollo de Centros de Cultura Popular (CCP), los que atendían las necesidades culturales de sindicatos, centros de reforma agraria, barrios y colegios en un intento por desarrollar una «cultura de masas» de carácter socialista.

Las ideas sobre la «revolución cultural» fueron expuestas por la revista Quinta Rueda de la editorial Quimantú, cuyo comité editorial estaba conformado, entre otros, por Carlos Maldonado y Antonio Skarmeta, este último, en 1970, había firmado el documento Politica Cultural. La revista, desde octubre de 1972, promocionó el vínculo entre artistas y el pueblo, el trabajo de los CCP y cuestionó que la política cultural a esas alturas aún no tuviera una relevancia significativa dentro del programa de gobierno, a este hecho debe su nombre.

Los problemas que debió enfrentar el gobierno de la Unidad Popular en 1973, dificultaron aún más la definición y aplicación de una política cultural, es por ello que las actividades culturales se enfocaron en mantener las relaciones entre el pueblo y el gobierno, tratando de algún modo afianzar la base de apoyo ante a la creciente polarización de la sociedad. En este contexto, el trabajo de los intelectuales quedó restringido a espacios como la revista Quinta Rueda, editorial Quimantú, ChileFilms, entre otras, en espera de una política que guiara su accionar. Dicha espera terminó el 11 de septiembre de 1973 con el golpe de Estado que clausuró la vía chilena al socialismo y la posibilidad de construir una nueva cultura.

\section{Conclusión}

En los años de la Unidad Popular, los escritores que firmaron la propuesta cultural, se sintieron llamados a ser parte del proyecto de transformaciones, planteando nuevos sentidos de realidad enmarcados en un marxismo renovado y en un compromiso con el proyecto socialista de la Unidad Popular.

Si bien las ideas de este grupo de literatos no cristalizaron como una política cultural, creemos que sus aportes dinamizaron el debate sobre lo cultural, manifestando, incluso, una postura que debatía con la Revolución Cubana. En tal sentido, la importancia de su intervención radica en la capacidad de construir una propuesta que buscaba la estimulación de la capacidad creadora del pueblo para superar la dependencia y el subdesarrollo a través de la ampliación del acceso a la educación, situando al intelectual como una vanguardia cultural que mediaba entre el aparato gubernamental y el pueblo, y haciendo un llamado a la conformación de un «Frente Único».

Desde el punto de vista histórico, esta investigación nos permitió conocer el accionar intelectual de este grupo de escritores, las visiones que tenían sobre la cultura y cómo debía ser la política cultural en la Unidad Popular, junto con relevar cuales eran, a juicio de estos escritores, las tareas del intelectual en un escenario de transición al socialismo y su relación con el campo político de la izquierda chilena. Al mismo tiempo, develó el debate en torno a lo cultural con el PC y las matrices marxistas con las que se construyeron las posiciones, en línea con pensadores que eran parte de un movimiento de renovación del marxismo como Kosík y Kolakowski.

Esto pone en evidencia, que en el periodo hubo una discusión sobre la política cultural, que en términos históricos manifiesta la conformación de proyectos, como el de los escritores del Taller, que, aunque quedaron enunciados y fueron polemizados, dan luces sobre lo que se pensaba en materia cultural y los actores que desarrollaron esas ideas. A partir de ello, se puede sostener que durante la Unidad Popular hubo una intensa discusión teórica respecto cómo construir la «nueva cultura».

Los discursos políticos enuncian diagnósticos y proposiciones que se fundan en expectativas, enmarcados en contextos que los articulan, en el caso de esta investigación, se puede sostener que la propuesta del grupo de escritores revisados estuvo marcada por la cultura de masas burguesa, las posibilidades de transformaciones que trajo consigo el triunfo de la Unidad Popular, la emergencia de un marxismo crítico que se distanciaba del determinismo económico y la re-formulación de la revolución 
cultural cubana. Todos estos hechos se conjugaron para que estos actores produjeran diversos documentos políticos con la clara intención de intervenir en el campo político.

\section{BIBLIOGRAFIA.}

-Carlos Maldonado. La revolución chilena y los problemas de la cultura. Santiago, Horizonte, 1971.

- César Albornoz, "La cultura en la Unidad Popular: Porque esta vez no se trata de cambiar un presidente". En: Julio Pinto, (Coordinador-editor), Cuando hicimos historia. La experiencia de la Unidad Popular. Santiago, LOM, 2006.

-Claudia Gilman. Entre la pluma y el fusil. Debates y dilemas del escritor revolucionario en América Latina. Buenos Aires, Siglo XXI editores Argentina, 2003.

-Cristián Huneeus. "El intelectual en su contribución al socialismo". VV.AA. La cultura en la vía chilena al socialismo. Santiago, Editorial Universitaria, 1971.

-Enrique Lihn. "Política y cultura en una etapa de transición al socialismo". VV.AA. La cultura en la vía chilena al socialismo. Santiago, Editorial Universitaria, 1971.

-Hernán Valdés. “¿Prudencia o desorientación para formular las bases de una política cultural?”. Cuadernos de la Realidad Nacional, Nº8, Junio 1971.

. "Ante la especulación y el divisionismo por una práctica cultural comprometida". VV.AA. La cultura en la vía chilena al socialismo. Santiago, Editorial Universitaria, 1971.

-"Política Cultural". Cormorán. Nº8. Diciembre 1970.

-Programa básico de gobierno de la Unidad Popular. Candidatura presidencial de Salvador Allende. 17de diciembre de 1969.

-Rolando Álvarez. “Trabajos voluntarios: el «hombre nuevo» y la creación de una nueva cultura en el Chile de la Unidad Popular". Pinto, Julio (Editor). Fiesta y drama. Nuevas historias de la Unidad Popular. Santiago, LOM, 2014.

-Soledad Bianchi. La memoria: modelo para armar. Santiago, Centro de investigaciones Diego Barros Arana, 1995.

- Volodia Teitelboim, "Intervención en Asamblea de Artistas e Intelectuales del Partido Comunista", La revolución chilena y los problemas de la cultural, Santiago, Horizonte, 1971.

\section{Digitales.}

-Ángel Rama. "Nueva política cultural cubana. Una autocrítica". Marcha N¹549, 25 de junio 1971, http://dspace.fic.edu.uy:8080/ispui/handle/123456789/1434

-Carla Rivera, "Diálogos y reflexiones sobre las comunicaciones en la Unidad Popular. Chile, 1970-1973", Historia y comunicación social, vol. 20, N², 2015.

http://revistas.ucm.es/index.php/HICS/article/view/51388/47668

-Carolina Fernández-Niño. "Revista Ramona (1971-1973). “... una revista lola que tomará los temas tangencialmente". Rolando Álvarez. Manuel Loyola (Eds.) Un trébol de cuatro hojas. Las Juventudes Comunistas de Chile en el siglo XX. Santiago, Ariadna, 2014.

http://ariadnaediciones.cl/images/pdf/Un.trebol.de.cuatro.hojas.pdf

- Germán Alburquerque, La trinchera letrada. Intelectuales latinoamericanos y la Guerra Fría, Ariadna, Santiago, 2011.

http://www.ariadnaediciones.cl/images/pdf/La.trinchera.letrada.pdf

-"I. Carta de Enrique Lihn", Marcha No 1541, Montevideo, 30 de abril de 1971

http://dspace.fic.edu.uy:8080/ispui/handle/123456789/1522

-Jaime Rosenblitt. "La reforma universitaria, 1967-1973". Cátedra Liderazgo Social 14 octubre - 18 noviembre 2010)

http://www.memoriachilena.cl/archivos2/pdfs/MC0014015.pdf. 
-Joaquín Brunner. Carlos Catalán. "Industria y mercado culturales en Chile: Descripción y cuantificaciones". Documento de trabajo Programa FLACSO N³59. Santiago, noviembre 1987, http://flacsochile.org/biblioteca/pub/memoria/1987/000272.pdf

- Jordi Magnet. "Karel Kosík, marxismo y heideggerianismo en los albores de la primavera de Praga", Revista Laguna, N³5, diciembre 2014, 113, https://riull.ull.es/xmlui/bitstream/handle/915/4319/L_35 \%282014\%29 06.pdf?sequence=1\&isAll owed $=\mathrm{y}$

-Karel Kosík. Dialéctica de lo concreto. México, Grijalbo, 1967. https://marxismocritico.files.wordpress.com/2012/05/dialecticadeloconcreto.pdf

-Mara Polgovsky. "La historia intelectual latinoamericana en la era del "giro lingüístico". Nuevo Mundo Mundos Nuevos. https:// nuevomundo.revues.org/60207

-Martín Bowen. "El proyecto sociocultural de la izquierda chilena durante la Unidad Popular. Crítica, verdad e inmunología política". Nuevos Mundos Nuevos Mundos. Debates, 21 de enero 2008. https://nuevomundo.revues.org/13732

-Nadine Canto. "El lugar de la cultura en la vía chilena al socialismo. Notas sobre el proyecto estético de la Unidad Popular". Pléyade, $N^{\circ}$ 9, Enero-Junio 2012, http://www.revistapleyade.cl/wpcontent/uploads/09.-Canto-UP.pdf

-Pilar González. "Sociabilidad y opinión pública en Buenos Aires (1821-1852)”. Historia Contemporánea. $\mathrm{N}^{\circ}$ 27. 2003, http://www.ehu.eus/ojs/index.php/HC/article/view/5205

. "La «sociabilidad» y la historia política". Nuevo Mundo. Mundos Nuevos. BAC - Biblioteca de Autores del Centro. 17 febrero 2008. https://nuevomundo.revues.org/24082

-"Sobre el caso Padilla", Marcha N 1539, Montevideo, 16 de abril de 1971

http://dspace.fic.edu.uy:8080/ispui/handle/123456789/1522 